\title{
Extracorporeal support for patients with acute respiratory distress syndrome
}

\author{
Simon J. Finney \\ Number 2 in the Series "Acute Respiratory Distress Syndrome" \\ Edited by S. John Wort and Stefano Nava
}

Affiliation: Adult Intensive Care Unit, Royal Brompton Hospital, London, UK.

Correspondence: Simon J. Finney, Adult Intensive Care Unit, Royal Brompton Hospital, Sydney Street, London, SW3 6NP, UK. E-mail: s.finneyवrbht.nhs.uk

ABSTRACT Extracorporeal membrane oxygen (ECMO) has been used for many years in patients with life-threatening hypoxaemia and/or hypercarbia. While early trials demonstrated that it was associated with poor outcomes and extensive haemorrhage, the technique has evolved. It now encompasses new technologies and understanding that the lung protective mechanical ventilation it can facilitate is inextricably linked to improving outcomes for patients.

The positive results from the CESAR (Conventional ventilation or ECMO for Severe Adult Respiratory failure) study and excellent outcomes in patients who suffered severe influenza A (H1N1/09) infection have established ECMO in the care of patients with severe acute respiratory distress syndrome. Controversy remains as to at what point in the clinical pathway ECMO should be employed; as a rescue therapy or more pro-actively to enable and ensure high-quality lung protective mechanical ventilation.

The primary aims of this article are to discuss: 1) the types of extracorporeal support available; 2) the rationale for its use; 3 ) the relationship with lung protective ventilation; and 4) the current evidence for its use.

0

@ERSpublications

ECMO and ARDS are inextricably linked to lung protection but when is tidal ventilation too injurious? http://ow.ly/yUJl7

\section{Introduction}

Variations of cardiopulmonary bypass have been used successfully in patients with severe acute respiratory distress syndrome (ARDS) since 1972 [1]. In a condition defined, in part, by refractory hypoxaemia its use is appealing. However, outcomes in early clinical trials were very poor $[2,3]$, and it was associated with severe haemorrhagic complications. Over the past 5 years, there has been an explosion in the number of patients receiving extracorporeal support for respiratory failure according to data from the international registry hosted by the Extracorporeal Life Support Organisation (ELSO). The associated increase in publications, including this one, and the flurry of hospitals opening "extracorporeal membrane oxygen (ECMO) centres" mirrors the enthusiasm for extracorporeal support and is a far cry from the time when many considered the practice as futile. What underpins the change in practice? Does ECMO support have a role in the care of patients with severe ARDS? When should it be employed in the complex patient pathway [4], which includes

Previous articles in this series: No. 1: Guérin C. Prone ventilation in acute respiratory distress syndrome. Eur Respir Rev 2014; 23: 249-257.

Received: June 202014 | Accepted after revision: July 022014

Conflict of interest: None declared.

Provenance: Submitted article, peer reviewed.

Copyright OERS 2014. ERR articles are open access and distributed under the terms of the Creative Commons Attribution Non-Commercial Licence 4.0. 
diagnosis, fluid management, careful mechanical ventilation, prone ventilation [5] and the avoidance of complications such as ventilator associated pneumonia?

\section{Terminology}

Extracorporeal life support (ECLS) is an umbrella term for all extracorporeal systems that provide support for the failing lung, heart or both. ECLS includes ECMO. During ECMO, a patient's blood is pumped through a membrane lung or oxygenator containing hollow polymethylpentene microfibres. Oxygencontaining gas passes through these microfibers, across the microfiber walls of which gas exchange occurs.

If blood is taken from the venous circulation and returned to the venous circulation (venovenous ECMO) then gas exchange occurs in a pre-pulmonary position and the effects of poor native lung function are obviated (fig. 1). Indeed, pre-pulmonary oxygenation can disrupt hypoxic pulmonary vasoconstriction further reducing the contribution of the native lung to gas exchange [6]. Venovenous ECMO has few circulatory effects aside from those resulting in a reduction in the pulmonary vascular resistance and modified cardiac preload, which occur due to oxygenation of pulmonary arterial blood, reduced hypercapnia, and the ability to reduce driving pressures on the mechanical ventilator.

In contrast, during venoarterial ECMO blood is passed from the venous to the arterial system and the flow of oxygenated blood into the arterial tree contributes to the global "cardiac" output of the body, thereby providing cardiac and respiratory support. Venoarterial ECMO may be peripheral, central or a hybrid of both, depending on the location of the cannulae that provide access to the circulation (fig. 2). Centrally positioned venous and arterial cannulae are usually in the right atrium and aortic root, respectively. Peripherally positioned venous and arterial cannulae are usually in the femoral/jugular veins and femoral/subclavian/ carotid arteries, respectively. Peripheral femoral arterial access results in retrograde flow in the aorta.

\section{Technology}

Modern ECMO circuits are relatively simple loops of tubing containing a pump and membrane (fig. 3). The technology has improved markedly with centrifugal pumps being employed in preference to roller pumps, polymethylpentene microfibre oxygenators used rather than silicone oxygenators, and bonding of antithrombotic agents to the inner lumen of the circuit. These anti-thrombotic agents are proprietary to different manufacturers, but include covalent bound heparins (e.g. Bioline (Maquet, Rastatt, Germany), Carmeda (Carmeda AB, Upplands Vasby, Sweden) and Rheoparin (Medos AG, Stolberg, Germany)) or hydrophobic/hydrophilic polymers (e.g. Softline (Maquet)). Cannulae have also improved, offering less resistance to flow, anti-thrombotic coatings and designs that minimise recirculation when in a dual lumen configuration. Together, these technological advances have simplified the circuit, made it less traumatic to blood and its components, reduced the need for anticoagulation, reduced the degree of systemic inflammation triggered by the circuit, and reduced the complications from a patient's perspective. Undoubtedly, the newer technology has eased the wider adoption of ECMO, but probably also shifted the risk-benefit balance in favour of ECMO support.

a)

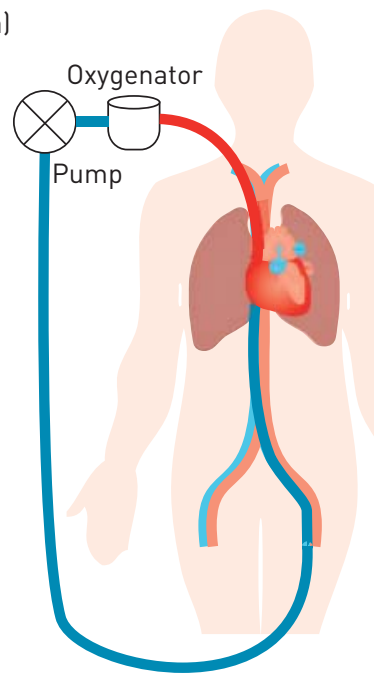

b)

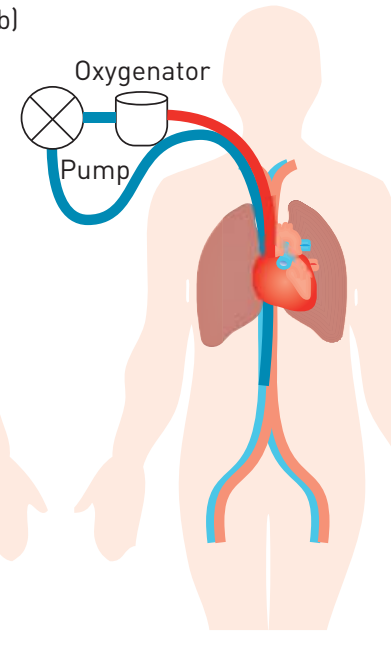

c)

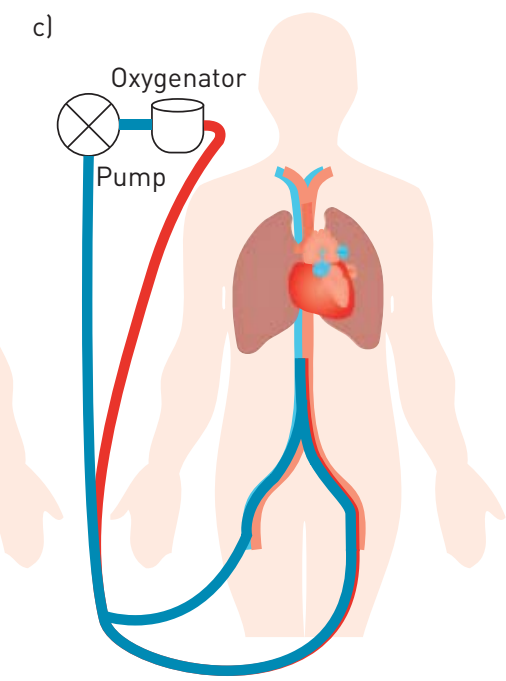

FIGURE 1 Common venovenous extracorporeal membrane oxygen configurations. a) Femoral-jugular cannulation, b) bicaval dual lumen cannulation of the right internal jugular, and c) femoral-femoral cannulation. 
a)

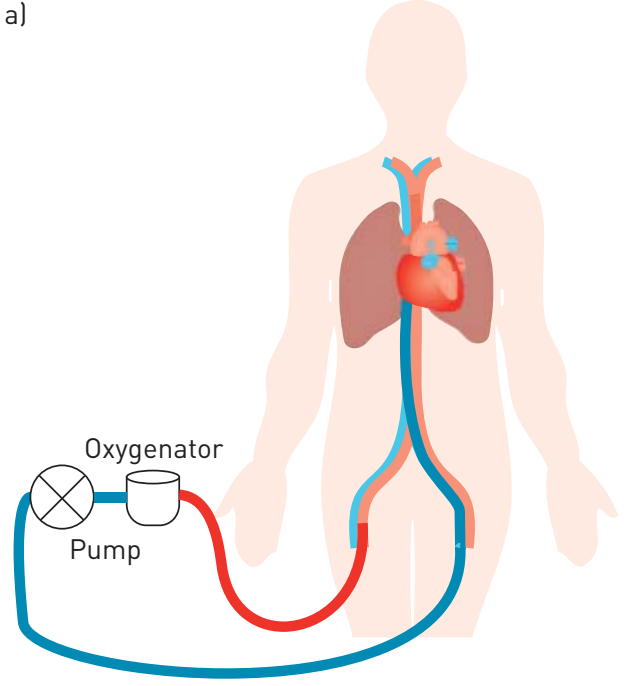

b)

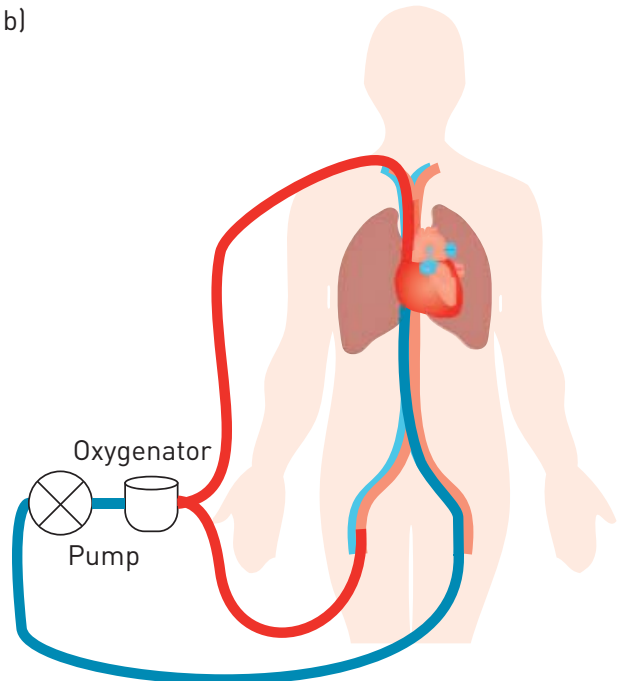

FIGURE 2 a) Venoarterial and b) venovenous arterial extracorporeal membrane oxygen configurations.

\section{Gas exchange in the membrane lung}

Gas exchange occurs across the walls of the microfibres in the membrane lung, which is governed by the principles of Fick's law of diffusion. The concentration gradient driving the flow of gas is the difference between the partial pressure of oxygen or carbon dioxide in blood and the sweep gas passing through the hollow fibres. During venovenous ECMO, blood entering the membrane lung has its oxygen saturation increased to $100 \%$ (fig. 4a). This equates to an increase of $\sim 35 \%$ and an increase in oxygen content of $\sim 50 \mathrm{~mL} \cdot \mathrm{L}^{-1}$. Oxygen uptake is enhanced by the simultaneous removal of carbon dioxide and alkalinisation of blood as it passes through the membrane lung (Bohr effect). To fulfil the resting oxygen requirements of an adult $\left(\sim 250 \mathrm{~mL} \cdot \mathrm{min}^{-1}\right)$, an ECMO blood flow of $\sim 5 \mathrm{~L} \cdot \mathrm{min}^{-1}$ would be needed. Systemic arterial saturations do not increase to $100 \%$ due to recirculation and the fact that the newly oxygenated blood is mixed with venous blood that has bypassed the cannula, which is effectively a physiological shunt. The oxygen content of blood in the circuit cannot be increased further within the circuit due to the $100 \%$ upper limit on saturations and the relative poor solubility of oxygen in plasma. Patient oxygenation can only be improved by increasing blood flow through the circuit and oxygenating proportionally more of the cardiac output. In practice, ECMO blood flow should be around two-thirds of the patient's cardiac output to provide acceptable arterial saturations. This can be difficult to achieve in patients who have sepsis and high cardiac outputs.

During venovenous ECMO, the greater solubility of blood for carbon dioxide and the flatter relationship between carbon dioxide tension and content means that the membrane lung removes $\sim 150 \mathrm{~mL} \cdot \mathrm{L}^{-1}$ of carbon dioxide from the blood (fig. 4b). Thus, the carbon dioxide production of a resting adult can be effectively removed at a blood flow of only $1.3 \mathrm{~L} \cdot \mathrm{min}^{-1}$. The Haldane effect enhances carbon dioxide removal as the blood is simultaneously oxygenated. The required blood flow is considerably less than that needed to support oxygenation, which has led to the development of several lower flow devices that aim to provide primarily extracorporeal carbon dioxide removal $\left(\mathrm{ECCO}_{2} \mathrm{R}\right)$ rather than oxygenation. Examples include the interventional Lung Assist (iLA; Novalung GmbH, Heilbronn, Germany), iLA Activve (Novalung GmbH), Hemolung (ALung Technologies Inc., Pittsburgh, PA, USA) and Pump-Assisted Lung Protection on the CardioHelp platform (Maquet, Rastatt, Germany). The advantages of lower flow devices have yet to be confirmed but may include the ability to use smaller, easier to place cannulae and less blood trauma due to the reduced shear stresses and reduced circuit pressures. The devices may be useful when hypercapnia but not hypoxaemia dominates the clinical scenario.

\section{Rationale}

Venovenous ECMO

Venovenous ECMO can restore the arterial blood gases of patients with refractory hypoxaemia and impaired tissue oxygen delivery or life threatening hypercarbia. Venovenous ECMO has often been deployed in these crises. It can also be used to facilitate lung protective ventilation, a central tenet in the care of patients with severe ARDS [7]. Indeed, ECMO and lung protective ventilation are inextricably linked. 


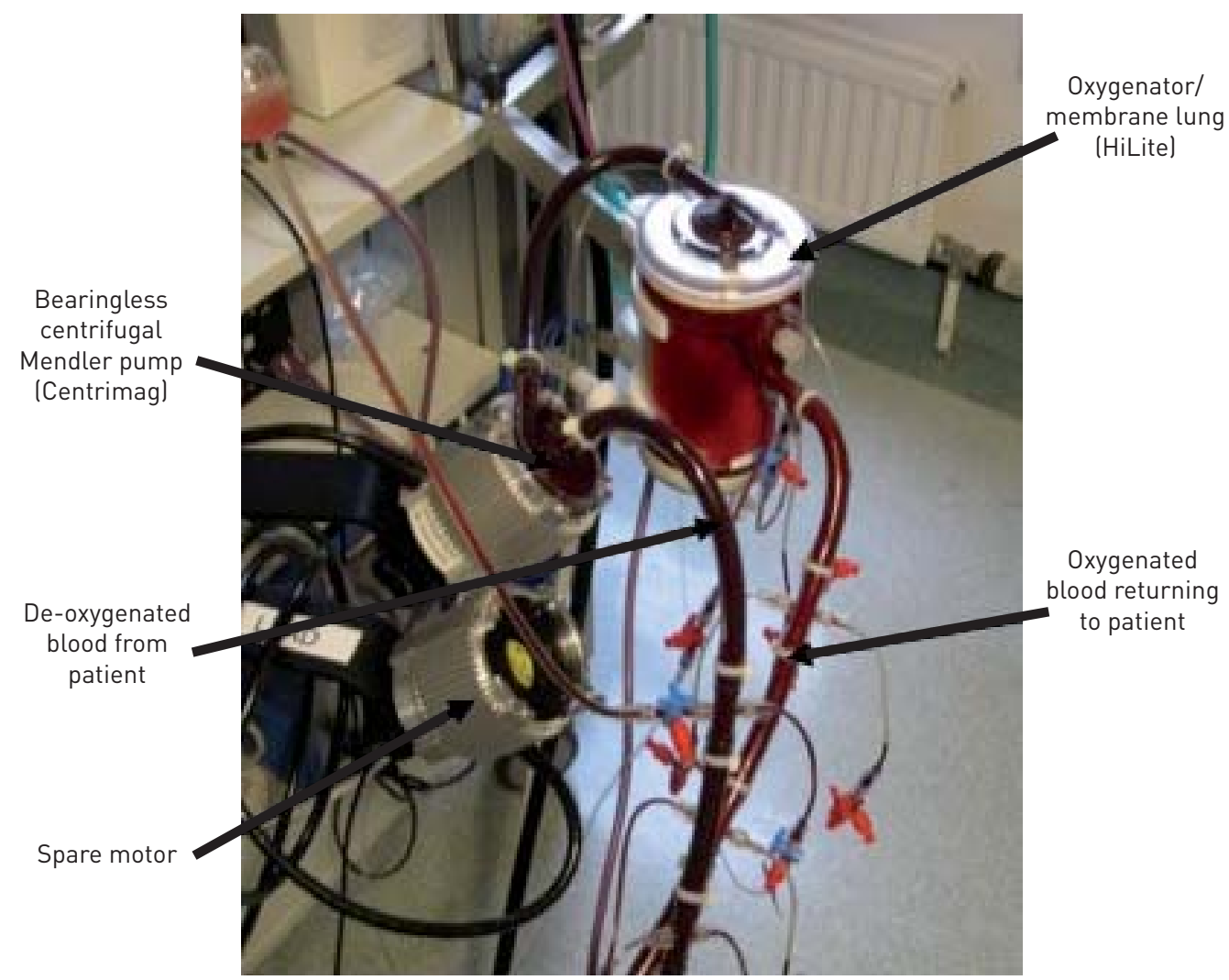

FIGURE 3 Typical extracorporeal membrane oxygen circuit. Centrimag is manufactured by Thoractec (Pleasanton, CA, USA) and HiLite is manufactured by Medos AG (Stolberg, Germany).

The landmark ARMA study published in 2000 demonstrated that patients with ARDS who received lower tidal volumes had reduced mortality, probably due to the associated reduction in multi-organ failure and systemic inflammation [8]. Tidal volume reduction is associated with arterial hypercapnia. Whilst this can be mitigated by increasing the respiratory frequency, lower respiratory rates may be protective in animal models of ventilator-induced lung injury $[9,10]$ and facilitate the prolongation of the inspiratory time, which in turn may enhance oxygenation through recruitment of long time-constant lung units. Oxygenation can be improved by high inspired oxygen concentrations or high airway pressures that may open up lung units. However, high airway pressures can cause cardiovascular compromise or injurious over distension of other areas of the lung. Similarly, high inspired oxygen concentrations may exacerbate pulmonary dysfunction [11], through the generation of toxic free radicals or promotion of atelectasis through nitrogen depletion. The conceptual shift cemented by the ARMA study was that poorly applied mechanical ventilation increased mortality and that there was a balance between accepting less than ideal arterial blood gases in order to avoid overly injurious mechanical ventilation [12].

The safe thresholds for arterial oxygen and carbon dioxide levels are not known. Arterial oxygen saturations are the key parameter that relates to oxygen delivery and should be the primary focus rather than the arterial oxygen tension. Indeed, the relationship between oxygen tension and saturation can be modified by many factors in critical illness. Many patients tolerate some desaturation without demonstrating signs of inadequate oxygen supply to the tissues, such as raised arterial lactate levels and impaired organ function. However, hypoxaemia has been associated with neurocognitive dysfunction in patients who survive ARDS [13]. Whilst the degree of hypoxaemia may be a surrogate for other processes, the concept of permissive severe hypoxaemia has never been tested [14], and cannot be advocated. Similarly, there is no specific arterial carbon dioxide tension $\left(\mathrm{PaCO}_{2}\right)$ that is known to be "safe". Survival has been reported for $\mathrm{PaCO}_{2}$ levels as high as $30 \mathrm{kPa}$ [15] and hypercapnia may limit pulmonary inflammation and injury [16]. In contrast, respiratory acidosis can be associated with cardiovascular instability and pulmonary hypertension. Typically a $\mathrm{PaCO}_{2}$ that results in a $\mathrm{pH}$ of $\geqslant 7.20$ is cited as "safe", although this threshold is based on animal data $[17,18]$ and has never been subject to formal investigation. 

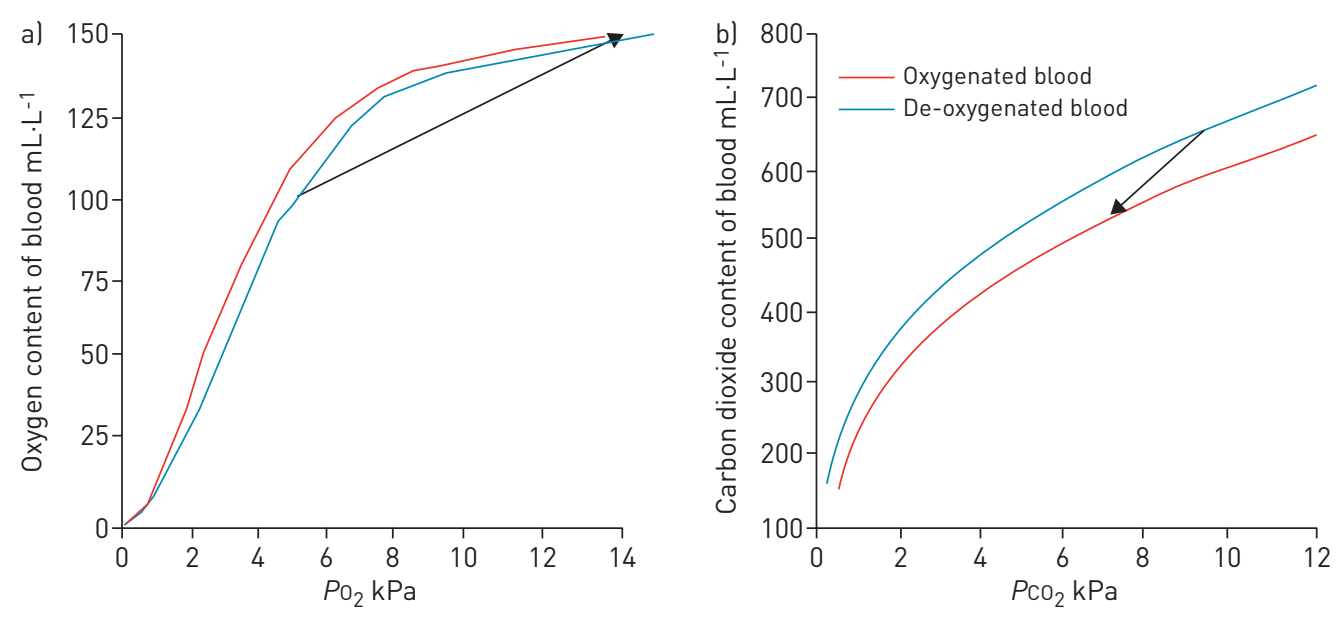

FIGURE 4 Oxygen uptake and carbon dioxide removal in the membrane lung. a) The oxygen dissociation curve for blood. b) The carbon dioxide dissociation curve for blood. The arrow represents the change in gas tension and gas content of blood that typically occurs in the membrane lung. Haemoglobin: $110 \mathrm{~g} \cdot \mathrm{L}^{-1} \cdot P_{2}$ : oxygen tension; $P_{C_{2}}$ : carbon dioxide tension.

What is the ideal tidal volume in a patient with ARDS? Some interpret the original ARMA study as demonstrating that the $12.1 \mathrm{~mL} \cdot \mathrm{kg}^{-1}$ tidal volume given to the control group in the study was injurious [19] but also not reflective of standard practice. The corollary and most conservative interpretation of the data is that the ARMA study proved that these tidal volumes must be avoided. However, most clinicians aim for a tidal volume of $6 \mathrm{~mL} \cdot \mathrm{kg}^{-1}$ predicted body weight, just fractionally less than the $6.2 \mathrm{~mL} \cdot \mathrm{kg}^{-1}$ delivered on days 1 and 3 in the lower tidal volume arm of the study. Calculation of predicted body weight from the patient's height is important but frequently not performed [20]. Analysis of 3000 consecutive admissions at the author's institution suggests that utilising actual body weight would result in $67 \%$ of patients being given a tidal volume $>10 \%$ of what was intended. Quick reference tables can assist clinicians at the bedside (table 1).

Tidal volumes of $6 \mathrm{~mL} \cdot \mathrm{kg}^{-1}$ are unlikely to be appropriate for all. Data from computed tomography (CT) examinations of patients with ARDS suggest that hyperinflation can be present, even at tidal volumes of $6 \mathrm{~mL} \cdot \mathrm{kg}^{-1}$ [21]. The group of patients with hyperinflation tended to need higher plateau pressures to achieve the $6 \mathrm{~mL} \cdot \mathrm{kg}^{-1}$ than those that had less hyperinflation $\left(28.9 \pm 0.9\right.$ versus $\left.25.5 \pm 0.5 \mathrm{cmH}_{2} \mathrm{O}\right)$. Subsequent studies demonstrated that hyperinflation was associated with more extensive consolidation on CT scans and increased levels of inflammatory cytokines (interleukin (IL)-6, IL-8, 1L-1 $\beta$ and IL-1 receptor antagonist) in bronchoalveolar lavage fluid. This cytokine signal was abolished within $72 \mathrm{~h}$ if the tidal

TABLE 1 Quick reference table for calculating upper tidal volume limit in acute respiratory distress syndrome

Height $\mathrm{cm}$

$6 \mathrm{~mL} \cdot \mathrm{kg}$ tidal volume $\mathrm{e}^{-1 \#}$

\begin{tabular}{ccc}
\hline Male & Female & \\
\hline & $140-145$ & 200 \\
$140-145$ & $145-150$ & 230 \\
$145-150$ & $150-155$ & 260 \\
$150-155$ & $155-160$ & 285 \\
$155-160$ & $160-165$ & 315 \\
$160-165$ & $165-170$ & 340 \\
$165-170$ & $170-175$ & 370 \\
$170-175$ & $175-180$ & 395 \\
$175-180$ & $180-185$ & 420 \\
$180-185$ & $185-190$ & 450 \\
$185-190$ & $190-195$ & 475 \\
$190-195$ & & 505 \\
\hline
\end{tabular}

The table presents approximate height range targets for males and females. ${ }^{\#}$ : calculated from the predicted body weight as determined in the ARMA study [8]. 
volume was reduced further to achieve a plateau pressure of $<28 \mathrm{cmH}_{2} \mathrm{O}$. Arterial hypercapnia was managed with $\mathrm{ECCO}_{2} \mathrm{R}$ if necessary [22]. The plateau pressure of $\sim 26 \mathrm{cmH}_{2} \mathrm{O}$ has appeared important in other settings. In a re-analysis of the patient receiving $6 \mathrm{~mL} \cdot \mathrm{kg}^{-1}$ tidal volumes in the ARMA study, there was a positive correlation between the required plateau pressure and mortality and an inflection point of $\sim 26 \mathrm{cmH}_{2} \mathrm{O}$ above which mortality increased more significantly [23]. In another study of patients receiving ECMO for severe influenza A infection, survivors had a mean plateau pressure of $25 \pm 3 \mathrm{cmH}_{2} \mathrm{O}$, in contrast to nonsurvivors who had a mean plateau pressure of $29 \pm 5 \mathrm{cmH}_{2} \mathrm{O}$ [24].

It is not known whether high tidal volumes are acceptable in patients who spontaneously trigger the mechanical ventilator with low ventilatory driving pressures. Spontaneous diaphragmatic activity may result in more homogenous ventilation. Often significant respiratory effort and very negative intrapleural pressures are masking poor lung compliance. A single animal study demonstrated significant pulmonary damage in sheep that hyperventilated following an injection of sodium salicylate into their cisterna magna [25]. This damage was not prevented by the administration of inspired carbon dioxide so as to maintain normocarbia during hyperventilation. Paralysis and mechanical ventilation with normal tidal volumes were not associated with pulmonary damage in the sheep. In general, many clinicians are equally concerned by high tidal volumes, whether they are mandatory or spontaneously triggered, although there are few data to support this assertion.

Taking these data together, my personal opinion as to what constitutes lung protective ventilation is a tidal volume of $\leqslant 6 \mathrm{~mL} \cdot \mathrm{kg}^{-1}$ predicted body weight so as to maintain the plateau pressure below $26 \mathrm{cmH}_{2} \mathrm{O}$. In the setting of lung resections, it is probably appropriate to reduce the tidal volume target further in proportion with the amount of lung resected. In the scenario of impaired chest wall mechanics, such as a marked kyphoscoliosis or extreme obesity, transpulmonary pressures will be less than anticipated and more liberal plateau pressures may be acceptable. These targets can be difficult to achieve with acceptable blood gases, particularly if significant amounts of positive end-expiratory pressure (PEEP) are used. The definition has never been subjected to a formal evaluation.

\section{Venoarterial ECMO}

Venoarterial ECMO is less frequently employed in ARDS unless there is significant associated cardiac dysfunction. Significant right ventricular dysfunction can occur in severe ARDS due to acute increases in the pulmonary vascular resistance. This can result in a low cardiac output state, although this often improves during venovenous ECMO as pulmonary vascular resistance falls due to oxygenation of pulmonary arterial blood, better carbon dioxide control and a reduction in mechanical ventilatory driving pressures. Severe sepsis can also cause significant myocardial dysfunction [26].

Peripheral venoarterial ECMO (fig. 2a) in the setting of severe pulmonary dysfunction and some residual cardiac function can result in an interesting phenomenon, often referred to as Harlequin syndrome [27]. Peripheral venous cannulae often do not drain the complete cardiac output through the circuit. This results in a residual native cardiac output through the heart and lungs. In the setting of severe respiratory failure blood will remain desaturated in the pulmonary vein and will ultimately be ejected from the left ventricle. This desaturated blood will meet well oxygenated blood from the ECMO circuit travelling up the aorta in a retrograde manner. The balance between the two circulations influences where the transition between deoxygenated and oxygenated blood occurs in the aortic arch. It is possible that the first vessels that leave the aorta (coronary arteries and vessels to the upper body) received deoxygenated blood from the left ventricle whilst the abdominal organs and lower body are supplied with oxygenated blood from the ECMO circuit. An elegant solution is to undertake a hybrid venovenous arterial ECMO approach (fig. 2b) where there is additional pre-pulmonary oxygenation.

\section{The risks of ECMO}

Bleeding complications are predominant in venoarterial ECMO and venovenous ECMO. Data from the international registry suggest that the incidence of gastrointestinal haemorrhage is $\sim 4 \%$, surgical site bleeding is $\sim 13 \%$ and cannulation site bleeding is $\sim 17 \%$ [28]. The most feared complication is intracranial haemorrhage, which is reported in $4-8 \%$ of cases [28-30]. It is not only associated with significant mortality but also significant functional impairment.

The risk of bleeding is not in keeping with the amount of heparin administered to prevent clotting within the extracorporeal circuit. ECMO is associated with other disorders of clotting, such as platelet dysfunction [31], acquired von Willebrand factor deficiency [32] and consumption of coagulation factors [33-35]. Bleeding can be massive and is best managed with the assistance of both surgical and haematological colleagues. It often requires multiple surgical procedures, large numbers of blood products [36] and temporary cessation of heparin therapy. 


\section{Evidence}

ECMO

ECMO has been tested in several studies. ZAPOL et al. [2] randomised 90 patients to receive venoarterial ECMO or ventilation alone. Mortality was $90.5 \%$ and $91.7 \%$ in the ECMO and control groups, respectively. Patients receiving ECMO support needed $1000-2500 \mathrm{~mL}$ of blood products each day. Patients died of relentlessly progressive respiratory failure, probably due to that fact that mechanical ventilation was not adjusted to what we now consider as protective settings. GATTINONi et al. [37] and MorRis et al. [3] investigated the effects of low flow ECMO, essentially carbon dioxide removal, to allow "lung rest", which was proposed as a reduction in respiratory rate to $\sim 3-4$ breaths per minute. Peak airway pressures were $>35 \mathrm{cmH}_{2} \mathrm{O}$. Whilst survival was improved in contrast to the previous study and historical controls, ECMO did not reduce mortality in comparison with conventional ventilation as practiced at that time. Blood loss remained $>1000 \mathrm{~mL}$ per day. These well undertaken studies need to be interpreted in the context of mechanical ventilation, which we would nowadays consider as injurious to the lung and patient.

Nevertheless, some centres demonstrated much better outcomes in venovenous ECMO [38]. This formed the basis for another randomised trial which was undertaken in the UK in 2009, the CESAR (Conventional ventilation or ECMO for Severe Adult Respiratory failure) study. In a heterogeneous group of patients with ARDS, this study demonstrated that transfer to an ECMO centre was associated with a $16 \%$ higher incidence of survival without severe disability. ECMO was provided along with a number of interventions, including fluid management and pressure-limited ventilation (peak airway pressure of $20-25 \mathrm{cmH}_{2} \mathrm{O}, \mathrm{PEEP}$ $10-15 \mathrm{cmH}_{2} \mathrm{O}$, respiratory rate of 10 breaths per $\min$ and fraction of inspired oxygen of 0.3 ). The limitations of the study have been widely discussed and include its single centre design, crossovers in that not all patients randomised to ECMO received ECMO, and lack of protocolised care in the conventionally managed arm. This resulted in differences between the groups that could have confounded the results. The higher use of corticosteroids and artificial liver support in patients cared for at the ECMO centre are unlikely to have impacted on survival, as neither have been demonstrated to influence mortality [39, 40]. In contrast, the greater use of low pressure and low volume ventilation in the patients at the ECMO centre could be a very significant confounder, representing better processes at the ECMO centre. Alternatively, and probably more likely, ECMO facilitated the persistent adoption of low tidal volumes and pressures and this was the mechanism of benefit in the study.

In the winters of 2009/2010 and 2010/2011, ECMO was used with success in the management of some patients with severe respiratory failure associated with pandemic influenza A (H1N1/09) infection. Case series demonstrated survival rates ranging from $64 \%$ to $72.5 \%$ in cohorts of patients who the attending clinicians felt were failing conventional therapies and had life-threatening hypoxaemia [24, 29, 30, 41]. The cases series all coupled ECMO support with robust lung protective ventilation. Two groups undertook casematched analyses to compare outcomes in the cohort of ECMO patients to similar patients identified in their national registries of patients admitted to intensive care units with H1N1/09 influenza A-related respiratory failure $[24,29]$. Matching was based on a priori defined variables that were considered to possibly impact upon outcome. The study from the UK demonstrated that mortality was approximately halved in patients who were referred and admitted to an ECMO centre [29]. In contrast, the French study demonstrated no difference in outcome [24]. The analyses differed in terms of the variables inputted into the models, statistical techniques and the size of the pool of potential case matches. Re-analysis of both datasets using the statistical techniques of the alternative manuscript continues to produce conflicting results. Interestingly, the service delivery model differs between the two countries with the 80 cases being centralised to five ECMO centres in the UK and 127 patients being cared for in 35 ECMO centres in France. How this impacts upon outcome is not known. Nevertheless, the excellent outcomes in patients with H1N1/ 09 influenza following the CESAR study have significantly contributed to the enthusiasm for ECMO in respiratory failure with refractory hypoxaemia. Overall, it appears that lung protective ventilation is an essential and non-negotiable part of the ECMO package. Indeed ECMO is only a method of support and does not directly impact on the underlying pulmonary process, aside from creating a scenario where mechanical ventilation may be less damaging. Indeed, it is not necessary to mechanically ventilate patients with ARDS who are on ECMO [42]. There is great interest in "awake ECMO" for patients with ARDS as it is proposed that this may avoid some of the deleterious effects of mechanical ventilation, sedation and immobilisation in the bed.

When ECMO should be employed remains controversial. Some would only employ it as rescue in catastrophic hypoxaemia. The CESAR study used, in part, the lung injury score or Murray score in an attempt to define severe respiratory failure that was failing conventional therapies but was not quite catastrophic or futile. The lung injury score is a composite score that ranges between 0 and 4 [43]. It evaluates PEEP, dynamic compliance, oxygenation and chest radiography. Higher values are meant to reflect worse lung injury. Patients were typically recruited at $\sim 36 \mathrm{~h}$ after tracheal intubation and mechanical 
ventilation. The ELOIA (Extracorporeal Membrane Oxygenation for Severe Acute Respiratory Distress Syndrome) study, an international multicentre randomised controlled trial, is investigating whether early implementation of ECMO within $6 \mathrm{~h}$ is beneficial (ClinicalTrials.gov identifier number NCT01470703). Current practice in the UK is to use the criteria employed in the CESAR study. Patients are considered for ECMO if they have a lung injury score $>3$ despite optimal management with lung protective ventilation. Optimal management probably also includes prone ventilation [44] and neuromuscular blockade. In some patients, the clinical decline is so rapid that there is insufficient time to optimise conventional therapy. Patients must have potentially reversible respiratory failure and have no contraindication to anticoagulation or ongoing life support. More than 7 days of injurious mechanical ventilation prior to ECMO is considered a relative contraindication as outcomes are significantly poorer in patients ventilated for a prolonged time prior to ECMO [45-49]. It is hypothesised that this is due to the irreversible establishment of significant ventilator-associated lung injury by prolonged injurious ventilation.

\section{$\mathrm{ECCO}_{2} \mathrm{R}$}

To date, there is one study of $\mathrm{ECCO}_{2} \mathrm{R}$ in 79 patients with moderate-to-severe ARDS and a plateau pressure $>25 \mathrm{cmH}_{2} \mathrm{O}$ [50]. The investigators hypothesised that a tidal volume $<6 \mathrm{~mL} \cdot \mathrm{kg}^{-1}$ would improve outcomes by further limiting ventilator-associated lung injury. Patients were randomised to receive tidal volumes of $6 \mathrm{~mL} \cdot \mathrm{kg}^{-1}$ or $3 \mathrm{~mL} \cdot \mathrm{kg}^{-1}$, the latter facilitated by the concomitant use of $\mathrm{ECCO}_{2} \mathrm{R}$. Patients with severe hypoxaemia received ECMO. The $\mathrm{ECCO}_{2} \mathrm{R}$ system used was the arteriovenous pumpless iLA (Novalung $\mathrm{GmbH})$. There were no differences in the primary outcomes of ventilator-free days at day 28 and day 60. Post hoc analysis suggested that patients who were more hypoxaemic and survived tended to wean faster and that it may be worth investigating the role of $\mathrm{ECCO}_{2} \mathrm{R}$ in this more severe group of patients. The SUPERNOVA (A Strategy of Ultra Protective Lung Ventilation with Extracorporeal $\mathrm{CO}_{2}$ Removal for New-Onset Moderate to Severe ARDS) study, backed by the European Society of Intensive Care Medicine, is currently being set up and may help answer this question. The patients in whom lung protective ventilation is difficult to achieve tend to have more extensive pulmonary consolidation and severe hypoxaemia. Thus, the size of the cohort of patients that may benefit from $\mathrm{ECCO}_{2} \mathrm{R}$ (whilst not requiring ECMO), and the lower blood flow in the extracorporeal circuit is not clear. The risk-benefit balance is also influenced by the relative effects of pulmonary oxygen toxicity, concomitant use of prone ventilation and acceptable oxygen saturations.

\section{Long-term outcomes in survivors of ECMO}

Rehabilitation following a period of respiratory ECMO can take a long time. Indeed, survivors of ARDS who do not require ECMO demonstrate changes over time when followed up for 5 years [51, 52]. Thus, assessments of health and quality of life will differ according to the time point at which they were measured. Nevertheless, ECMO survivors have comparable outcomes to those who did not need ECMO when this is assessed using the 36-item Short-Form Health Survey (SF-36) or EuroQoL questionnaire [53-55], although this is less than for an age- and sex-matched population. Return to work is often limited or delayed [53] and there are significant psychological sequelae [56]. Nevertheless, respiratory ECMO patients score higher on the individual domains of the SF-36 than patients on chronic renal dialysis or patients who suffer with New York Heart Association class III heart failure [57, 58].

\section{Models of care}

ECMO support requires assistance from many specialities within an organisation, including clinical perfusion, haematology and surgery. Bedside nurses and critical care physicians need specific knowledge and competencies to safely maintain the circuit. Often patients are absolutely dependent on the circuit and may not be able to survive a failure triggered by inadvertent air entrainment or thrombosis. There are modifications to many of the other intensive care unit processes too. For example, the routine and seemingly innocuous insertion of a nasogastric feeding tube can be associated with massive haemorrhage. This brings a burden of training to an ECMO centre that is not insignificant. ELSO have endeavoured to define the knowledge and competencies that ECMO specialists require [59].

Other care is essential for a patient with severe respiratory failure. The vital nature of appropriate mechanical ventilation has been described previously. Ensuring the correct diagnosis is made, avoiding ventilator-associated pneumonia, managing pneumothoraces and air leaks, careful fluid management and rehabilitation are also important. This requires radiologists, sub-speciality respiratory physicians, cardiologists, thoracic surgeons, infectious disease specialists, and therapists and physicians expert in rehabilitation following an episode of severe critical illness.

The training burden and infrastructure requirements favour the regionalisation of care to ECMO centres. Regionalisation of care mandates that referral centres can provide mobile ECMO services so patients admitted to other institutions can receive definitive support as soon as possible. There are some data that 
suggest that increased numbers of cases may be associated with better outcomes for mechanical ventilation per se [60] and ECMO [61, 62]. This relationship is far from proven and other factors, such as organisation culture and an ability to learn, have a huge impact. Undoubtedly low volume centres have to consider and make special governance arrangements to sustain their knowledge and competencies. The development of risk-adjustment models may facilitate benchmarking between centres [45, 47].

\section{Conclusion}

Venovenous ECMO support can avert life threatening hypoxaemia and hypercapnia, and can crucially facilitate lung protective ventilation in patients with severe ARDS. The CESAR study demonstrated improved survival without severe disability in patients transferred to an ECMO centre. Patients with influenza A (H1N1/09) had good outcomes on ECMO. These results may corroborate the results from CESAR but might not be generalisable outside the population of patients with severe influenza respiratory disease. Nevertheless, ECMO centres continue to report high survival rates for patients who are supported with ECMO. The patients return to a reasonable quality of life, albeit over a rehabilitation period that is often very prolonged. The main controversy regarding ECMO is when should it be employed? As a rescue therapy in profound hyopoxaemia and hypercarbia or earlier in the natural history of the process to enhance lung protective ventilation? The ELOIA and SUPERNOVA studies will endeavour to answer these questions.

\section{References}

1 Hill JD, O’Brien TG, Murray JJ, et al. Prolonged extracorporeal oxygenation for acute post-traumatic respiratory failure (shock-lung syndrome). Use of the Bramson membrane lung. N Engl J Med 1972; 286: 629-634.

2 Zapol WM, Snider MT, Hill JD, et al. Extracorporeal membrane oxygenation in severe acute respiratory failure. A randomized prospective study. JAMA 1979; 242: 2193-2196.

3 Morris AH, Wallace CJ, Menlove RL, et al. Randomized clinical trial of pressure-controlled inverse ratio ventilation and extracorporeal $\mathrm{CO}_{2}$ removal for adult respiratory distress syndrome. Am J Respir Crit Care Med 1994; 149: 295-305.

4 Wort SJ, Price L, Nava S. Topics in acute respiratory distress syndrome: the patient needs our tender loving and care. Eur Respir Rev 2014; 23: 157-160.

5 Guérin C. Prone ventilation in acute respiratory distress syndrome. Eur Respir Rev 2014; 23: 249-257.

6 Lamy M, Eberhart RC, Fallat RJ, et al. Effects of extracorporeal membrane oxygenation (ECMO) on pulmonary hemodynamics, gas exchange and prognose. Trans Am Soc Artif Intern Organs 1975; 21: 188-198.

7 Salman D, Finney SJ, Griffiths MJ. Strategies to reduce ventilator-associated lung injury (VALI). Burns 2013; 39: 200-211.

8 Ventilation with lower tidal volumes as compared with traditional tidal volumes for acute lung injury and the acute respiratory distress syndrome. The Acute Respiratory Distress Syndrome Network. N Engl J Med 2000; 342: 1301-1308.

9 Vaporidi K, Voloudakis G, Priniannakis G, et al. Effects of respiratory rate on ventilator-induced lung injury at a constant $\mathrm{Pa}, \mathrm{CO}_{2}$ in a mouse model of normal lung. Crit Care Med 2008; 36: 1277-1283.

10 Conrad SA, Zhang S, Arnold TC, et al. Protective effects of low respiratory frequency in experimental ventilatorassociated lung injury. Crit Care Med 2005; 33: 835-840.

11 Auten RL, Davis JM. Oxygen toxicity and reactive oxygen species: the devil is in the details. Pediatr Res 2009; 66: 121-127.

12 Hickling KG, Walsh J, Henderson S, et al. Low mortality rate in adult respiratory distress syndrome using lowvolume, pressure-limited ventilation with permissive hypercapnia: a prospective study. Crit Care Med 1994; 22: $1568-1578$.

13 Mikkelsen ME, Christie JD, Lanken PN, et al. The adult respiratory distress syndrome cognitive outcomes study: long-term neuropsychological function in survivors of acute lung injury. Am J Respir Crit Care Med 2012; 185: $1307-1315$.

14 Gilbert-Kawai ET, Mitchell K, Martin D, et al. Permissive hypoxaemia versus normoxaemia for mechanically ventilated critically ill patients. Cochrane Database Syst Rev 2014; 5: CD009931.

15 Urwin L, Murphy R, Robertson C, et al. A case of extreme hypercapnia: implications for the prehospital and accident and emergency department management of acutely dyspnoeic patients. Emerg Med J 2004; 21: 119-120.

16 Ijland MM, Heunks LM, van der Hoeven JG. Bench-to-bedside review: hypercapnic acidosis in lung injury - from "permissive" to "therapeutic". Crit Care 2010; 14: 237.

17 Steenbergen C, Deleeuw G, Rich T, et al. Effects of acidosis and ischemia on contractility and intracellular pH of rat heart. Circ Res 1977; 41: 849-858.

18 Wildenthal K, Mierzwiak DS, Myers RW, et al. Effects of acute lactic acidosis on left ventricular performance. Am J Physiol 1968; 214: 1352-1359.

19 Eichacker PQ, Gerstenberger EP, Banks SM, et al. Meta-analysis of acute lung injury and acute respiratory distress syndrome trials testing low tidal volumes. Am J Respir Crit Care Med 2002; 166: 1510-1514.

20 Tallach R, Jefferson P, Ball DR. Mechanical ventilation for patients with ARDS: a UK survey on calculation of tidal volume. Intensive Care Med 2006; 32: 176

21 Terragni PP, Rosboch G, Tealdi A, et al. Tidal hyperinflation during low tidal volume ventilation in acute respiratory distress syndrome. Am J Respir Crit Care Med 2007; 175: 160-166.

22 Terragni PP, Del Sorbo L, Mascia L, et al. Tidal volume lower than $6 \mathrm{ml} / \mathrm{kg}$ enhances lung protection: role of extracorporeal carbon dioxide removal. Anesthesiology 2009; 111: 826-835.

23 Hager DN, Krishnan JA, Hayden DL, et al. Tidal volume reduction in patients with acute lung injury when plateau pressures are not high. Am J Respir Crit Care Med 2005; 172: 1241-1245. 
Pham T, Combes A, Roze H, et al. Extracorporeal membrane oxygenation for pandemic influenza A(H1N1)induced acute respiratory distress syndrome: a cohort study and propensity-matched analysis. Am J Respir Crit Care Med 2013; 187: 276-285.

25 Mascheroni D, Kolobow T, Fumagalli R, et al. Acute respiratory failure following pharmacologically induced hyperventilation: an experimental animal study. Intensive Care Med 1988; 15: 8-14.

26 Parker MM, Shelhamer JH, Bacharach SL, et al. Profound but reversible myocardial depression in patients with septic shock. Ann Intern Med 1984; 100: 483-490.

27 Avgerinos DV, DeBois W, Voevidko L, et al. Regional variation in arterial saturation and oxygen delivery during venoarterial extracorporeal membrane oxygenation. J Extra Corpor Technol 2013; 45: 183-186.

28 Extracorporeal Life Support Organization. ECLS Registry Report. International Summary 2014. www.elso.org/ index.php? option $=$ com_content\&view $=$ article\&id $=85 \&$ Itemid $=653$ Date last updated: January, 2014. Date last accessed: July 1, 2014.

29 Noah MA, Peek GJ, Finney SJ, et al. Referral to an extracorporeal membrane oxygenation center and mortality among patients with severe 2009 influenza A (H1N1). JAMA 2011; 306: 1659-1668.

30 Australia and New Zealand Extracorporeal Membrane Oxygenation Influenza Investigators, Davies A, Jones D, et al. Extracorporeal membrane oxygenation for 2009 influenza A (H1N1) acute respiratory distress syndrome. JAMA 2009; 302: 1888-1895.

31 Bevan DH. Cardiac bypass haemostasis: putting blood through the mill. Br J Haematol 1999; 104: $208-219$.

32 Heilmann C, Geisen U, Beyersdorf F, et al. Acquired von Willebrand syndrome in patients with extracorporeal life support (ECLS). Intensive Care Med 2012; 38: 62-68.

33 Woodman RC, Harker LA. Bleeding complications associated with cardiopulmonary bypass. Blood 1990; 76: 1680-1697.

34 Bachmann F, McKenna R, Cole ER, et al. The hemostatic mechanism after open-heart surgery. I. Studies on plasma coagulation factors and fibrinolysis in 512 patients after extracorporeal circulation. J Thorac Cardiovasc Surg 1975; 70: 76-85.

35 Mammen EF, Koets MH, Washington BC, et al. Hemostasis changes during cardiopulmonary bypass surgery. Semin Thromb Hemost 1985; 11: 281-292.

36 Davidson S. State of the art - how I manage coagulopathy in cardiac surgery patients. Br J Haematol 2014; 164: 779-789.

37 Gattinoni L, Pesenti A, Mascheroni D, et al. Low-frequency positive-pressure ventilation with extracorporeal $\mathrm{CO}_{2}$ removal in severe acute respiratory failure. JAMA 1986; 256: 881-886.

38 Peek GJ, Moore HM, Moore N, et al. Extracorporeal membrane oxygenation for adult respiratory failure. Chest 1997; 112: 759-764.

39 Steinberg KP, Hudson LD, Goodman RB, et al. Efficacy and safety of corticosteroids for persistent acute respiratory distress syndrome. N Engl J Med 2006; 354: 1671-1684.

40 Vaid A, Chweich H, Balk EM, et al. Molecular adsorbent recirculating system as artificial support therapy for liver failure: a meta-analysis. ASAIO J 2012; 58: 51-59.

41 Patroniti N, Zangrillo A, Pappalardo F, et al. The Italian ECMO network experience during the 2009 influenza A (H1N1) pandemic: preparation for severe respiratory emergency outbreaks. Intensive Care Med 2011; 37: 1447-1457.

42 Wiesner O, Hadem J, Sommer W, et al. Extracorporeal membrane oxygenation in a nonintubated patient with acute respiratory distress syndrome. Eur Respir J 2012; 40: 1296-1298.

43 Murray JF, Matthay MA, Luce JM, et al. An expanded definition of the adult respiratory distress syndrome. Am Rev Respir Dis 1988; 138: 720-723.

44 Guérin C, Reignier J, Richard JC. Prone positioning in the acute respiratory distress syndrome. N Engl J Med 2013; 369: 980-981.

45 Schmidt M, Bailey M, Sheldrake J, et al. Predicting survival after extracorporeal membrane oxygenation for severe acute respiratory failure. The Respiratory Extracorporeal Membrane Oxygenation Survival Prediction (RESP) Score. Am J Respir Crit Care Med 2014; 189: 1374-1382.

46 Brogan TV, Thiagarajan RR, Rycus PT, et al. Extracorporeal membrane oxygenation in adults with severe respiratory failure: a multi-center database. Intensive Care Med 2009; 35: 2105-2114.

47 Schmidt M, Zogheib E, Roze H, et al. The PRESERVE mortality risk score and analysis of long-term outcomes after extracorporeal membrane oxygenation for severe acute respiratory distress syndrome. Intensive Care Med 2013; 39: 1704-1713.

48 Beiderlinden M, Eikermann M, Boes T, et al. Treatment of severe acute respiratory distress syndrome: role of extracorporeal gas exchange. Intensive Care Med 2006; 32: 1627-1631.

49 Hemmila MR, Rowe SA, Boules TN, et al. Extracorporeal life support for severe acute respiratory distress syndrome in adults. Ann Surg 2004; 240: 595-605.

50 Bein $\mathrm{T}$, Weber-Carstens S, Goldmann A, et al. Lower tidal volume strategy ( $\approx 3 \mathrm{ml} / \mathrm{kg})$ combined with extracorporeal $\mathrm{CO}_{2}$ removal versus "conventional" protective ventilation $(6 \mathrm{ml} / \mathrm{kg})$ in severe ARDS. Intensive Care Med 2013; 39: 847-856.

51 Herridge MS, Tansey CM, Matte A, et al. Functional disability 5 years after acute respiratory distress syndrome. N Engl J Med 2011; 364: 1293-1304.

52 Herridge MS, Cheung AM, Tansey CM, et al. One-year outcomes in survivors of the acute respiratory distress syndrome. N Engl J Med 2003; 348: 683-693.

53 Hodgson CL, Hayes K, Everard T, et al. Long-term quality of life in patients with acute respiratory distress syndrome requiring extracorporeal membrane oxygenation for refractory hypoxaemia. Crit Care 2012; 16: R202.

54 Luyt CE, Combes A, Becquemin MH, et al. Long-term outcomes of pandemic 2009 influenza A (H1N1)-associated severe ARDS. Chest 2012; 142: 583-592.

55 Peek GJ, Mugford M, Tiruvoipati R, et al. Efficacy and economic assessment of conventional ventilatory support versus extracorporeal membrane oxygenation for severe adult respiratory failure (CESAR): a multicentre randomised controlled trial. Lancet 2009; 374: 1351-1363.

56 Risnes I, Heldal A, Wagner K, et al. Psychiatric outcome after severe cardio-respiratory failure treated with extracorporeal membrane oxygenation: a case-series. Psychosomatics 2013; 54: 418-427. 
57 Merkus MP, Jager KJ, Dekker FW, et al. Quality of life in patients on chronic dialysis: self-assessment 3 months after the start of treatment. The Necosad Study Group. Am J Kidney Dis 1997; 29: 584-592.

58 Juenger J, Schellberg D, Kraemer S, et al. Health related quality of life in patients with congestive heart failure: comparison with other chronic diseases and relation to functional variables. Heart 2002; 87: 235-241.

59 Extracorporeal Life Support Organization. ELSO guidelines for training and continuing education of ECMO specialists. Version 1.5. www.elso.org/downloads/resources/guidelines/elso\%20guidelines $\% 20$ for $\% 20$ training $\% 20$ and $\%$ 20continuing\%20education\%20of\%20ecmo\%20specialists.pdf Date last updated: February, 2010. Date last accessed: July 1, 2014.

60 Kahn JM, Goss CH, Heagerty PJ, et al. Hospital volume and the outcomes of mechanical ventilation. N Engl J Med 2006; 355: 41-50.

61 Freeman CL, Bennett TD, Casper TC, et al. Pediatric and neonatal extracorporeal membrane oxygenation: does center volume impact mortality? Crit Care Med 2014; 42: 512-519.

62 Karamlou T, Vafaeezadeh M, Parrish AM, et al. Increased extracorporeal membrane oxygenation center case volume is associated with improved extracorporeal membrane oxygenation survival among pediatric patients. J Thorac Cardiovasc Surg 2013; 145: 470-475. 